OPEN ACCESS

Edited by:

Gabriella Martino,

University of Messina, Italy

Reviewed by:

Annalisa Tanzilli,

Sapienza University of Rome, Italy

*Correspondence:

Ciro Conversano

ciro.conversano@unipi.it

Specialty section:

This article was submitted to

Psychopathology,

a section of the journal

Frontiers in Psychology

Received: 20 February 2021

Accepted: 15 March 2021

Published: 09 April 2021

Citation:

Conversano C (2021) The

Psychodynamic Approach During COVID-19 Emotional Crisis.

Front. Psychol. 12:670196.

doi: 10.3389/fpsyg.2021.670196

\section{The Psychodynamic Approach During COVID-19 Emotional Crisis}

\author{
Ciro Conversano* \\ Department of Surgical, Medical and Molecular Pathology, Critical and Care Medicine, University of Pisa, Pisa, Italy
}

Keywords: psychodynamic, psychodynamic approach, clinical psychology, mental health, COVID-19, COVID-19 outbreak, psychotherapy, psychodinamic psychotherapy

The psychodynamic approach views human behavior from the standpoint of unconscious motives that influence personality functioning. In contrast with a nosological approach, the emphasis is on tracing behavior to its origins, fostering a deeper understanding of what is "behind" the overt signs and symptoms of disorder (Vaillant, 1977, 1992; Kernberg, 1988; Gabbard, 2014; Sartori et al., 2017; Mazza et al., 2019). From the early stage of development, the individual experiences life in peculiar ways that will progressively determine one's identity, including attitudes, coping strategies, cognitive processes, and relational dynamics (Cramer, 2007; Fonagy et al., 2008; Di Giuseppe et al., 2019b; Rosa et al., 2019; Giovanardi et al., 2020). Psychodynamic theories have offered a remarkable contribution to the study of unconscious processes connected with physical and mental distress. This approach has helped scholars in understanding the link between body and mind, detecting cyclical relational patterns, meaning individuals' behaviors and treating psychopathologies from an emotion-focused perspective (Bornstein, 2005; Bateman and Fonagy, 2012; Luyten and Blatt, 2015; Salvatore et al., 2015; Hilsenroth et al., 2018; McCarthy et al., 2019; Salvatore, 2019).

The impact of a dynamic approach in psychotherapy is largely documented (Midgley et al., 2009; Perry and Bond, 2012; Hilsenroth and Pitman, 2019; Lo Coco et al., 2019a; Gelo et al., 2020; Gennaro et al., 2020). Process-outcome research has highlighted the effectiveness of dynamic psychotherapy in treating various mental disorder such as depression (Meystre et al., 2017; Starrs and Perry, 2018; Perry et al., 2020), anxiety (Maffei et al., 1995; Babl et al., 2019; Solomonov et al., 2019) eating disorders (Gelo et al., 2015; Lo Coco et al., 2021), pathologic addictions (Terrone et al., 2018; Frisone et al., 2020; Lo Coco et al., 2020; Giordano et al., 2021), psychotic traits (Boldrini et al., 2019, 2020), externalizing problems (Prout et al., 2018a; Hoffman and Prout, 2020), and personality disfunction (Lingiardi and Giovanardi, 2017; Goldman et al., 2018; Aafjes-van Doorn et al., 2019; Kramer, 2019; Di Giuseppe et al., 2020b; Solomonov et al., 2020). The role of therapeutic alliance as mediator on outcomes in psychotherapy has been demonstrated in several studies highlighting the need for an in-depth investigation of patient-therapist communicative exchange (Lingiardi et al., 2010; Perry, 2014; Bhatia et al., 2017; Salvatore et al., 2017; Rocco et al., 2018; Tanzilli et al., 2018; Lo Coco et al., 2019b; Leibovich et al., 2020; Zilcha-Mano et al., 2020).

\section{THE PSYCHODYNAMIC APPROACH AGAINST COVID-RELATED PSYCHOLOGICAL CONSEQUENCES}

The health emergency we are experiencing due to COVID-19 has strongly influenced not only physical health but also the mental health of the general population as well as collective behavior (Gray et al., 2020; Orrù et al., 2020b; Lenzo et al., 2021). The understanding of mental health consequences must consider individual emotional responses associated with the ongoing stressful experience of the COVID-19 pandemic (Di Giuseppe et al., 2020a; Venuleo et al., 2020). Negative 
emotions such as fear, anger, frustration and significant economic worries are associated with higher levels of anxiety, depression, sleep disturbances, maladaptive behaviors, and psychosomatic symptoms (Conversano et al., 2020b; Franceschini et al., 2020; Parola et al., 2020). As expected, the severity of clinical conditions is observed to be higher in vulnerable groups such as children, the elderly, psychiatric patients, and front-line workers (Aafjesvan Doorn et al., 2020b; Elbay et al., 2020; Elkholy et al., 2020; Merlo et al., 2020; Shen et al., 2020; Singh et al., 2020; Orrù et al., 2021). Research has demonstrated that emotion regulation plays a key role in stress management and adaptation helping the individual to cope with discharged feelings and thoughts related to the COVID-19 crisis, communication of the final stage of the individual's life (Iasevoli et al., 2012) and, therefore, protecting them from developing clinical levels of psychological distress (Di Giuseppe et al., 2020e; Prout et al., 2020; Walker and McCabe, 2021). The role of dynamic psychotherapy is essential in moderating people's emotional reactions, although its implementation requires the adjustment of therapeutic strategies enhancing adaptation and resilience (Aafjes-van Doorn et al., 2020a; Békés et al., 2020). From this perspective, it is imperative to improve public awareness and establish adequate procedures and prompt responses of intervention.

Due to uncertainty surrounding COVID-19, collective distress and individual suffering, the psychodynamic approach may be able to consistently identify and manage stressful lifeevent dynamics (Afari et al., 2014; Di Giuseppe et al., 2019a) as well as fostering emotional regulation in order to prevent possible relevant factors involved in the pathogenesis of both psychological and psychosomatic syndromes (Lenzo et al., 2020; Martino et al., 2020a,b; Conversano and Di Giuseppe, 2021; Sardella et al., 2021). This is of particular relevance at present with many experiencing grief and sorrow for the loss of a family member, a reduction of freedom, changes in daily routines and fears associated with uncertainty and the intolerance of uncertainty (Conversano et al., 2020a; Orrù et al., 2020a). In response to these stressors, the individual activates unconscious defense mechanisms, psychological strategies that help in reducing the anxiety associated with the awareness of internal conflicts and externally-charged situations (Perry, 1990; American Psychiatric Association, 2013). Since defense mechanisms are hierarchically organized and own specific psychological functions, they may cause a

\section{REFERENCES}

Aafjes-van Doorn, K., Békés, V., and Prout, T. A. (2020a). Grappling with our therapeutic relationship and professional self-doubt during covid-19: will we use video therapy again? Couns. Psychol. Q. doi: 10.1080/09515070.2020.1773404

Aafjes-van Doorn, K., Békés, V., Prout, T. A., and Hoffman, L. (2020b). Psychotherapists' vicarious traumatization during the COVID-19 pandemic. Psychol. Trauma 12, S148-S150. doi: 10.1037/tra0000868

Aafjes-van Doorn, K., Kealy, D., Ehrenthal, J. C., Ogrodniczuk, J. S., Joyce, A. S., and Weber, R. (2019). Improving self-esteem through integrative group therapy for personality dysfunction: Investigating the role of the therapeutic wide number of negative consequences as well as playing a significant role as protective factors against psychological distress and psychopathological symptoms caused by the COVID-19 outbreak (Marazziti et al., 2020). The use of high-adaptive defense mechanisms promotes increased awareness of one owns feelings related to difficult life experiences and leads to better adjustment and resilience, whereas the use of immature defenses protects the self from painful feelings and thoughts at the cost of developing maladaptive affective, cognitive and relational disfunctions (Di Giuseppe et al., 2014; Perry et al., 2019). Recent studies demonstrate that specific therapeutic intervention may increase the overall defensive maturity and improve psychological well-being and adjustment (Hoffman et al., 2016; Prout et al., 2018b, 2019; Di Giuseppe et al., 2020d).

\section{CONCLUSIONS}

In this opinion article the relevance of the implementing psychodynamic approach in the prevention of individuals' mental health during the ongoing COVID-19 crisis has been highlighted. In accordance with Marčinko et al. (2020), the inclusion of psychodynamic interventions within the public mental health emergency system is recommended, considered as an effective strategy in reinforcing the individual's well-being both during and after the COVID-19 pandemic crisis. The application of specific therapeutic interventions derived from the psychodynamic approach can enhance emotion regulation and adaptive responses as the COVID-19 pandemic progresses.

Understanding how the ongoing pandemic is influencing human reactions to such a stressful event is essential for developing ad hoc effective interventions. The systematic assessment of unconscious psychological aspects of personality should be promoted for the early detection of vulnerable individuals and for improving research and clinical practice toward a personalized therapeutic approach (Lingiardi and McWilliams, 2015; Lingiardi et al., 2015; Tanzilli et al., 2016; Barber and Solomonov, 2019; Talia et al., 2019; Di Giuseppe et al., 2020c; Zilcha-Mano and Ramseyer, 2020).

\section{AUTHOR CONTRIBUTIONS}

The author confirms being the sole contributor to this work and approves it for publication. alliance and quality of object relations. J. Clin. Psychol. 75, 2079-2094. doi: $10.1002 /$ jclp. 22832

Afari, N., Ahumada, S. M., Wright, L. J., Mostoufi, S., Golnari, G., Reis, V., et al. (2014). Psychological trauma and functional somatic syndromes: a systematic review and meta-analysis. Psychosom. Med. 76, 2-11. doi: 10.1097/PSY.0000000000000010

American Psychiatric Association (2013). Diagnostic and Statistical Manual of Mental Disorders. 5th Edn. Washington, DC: American Psychiatric Association. doi: 10.1176/appi.books.9780890425596

Babl, A., Grosse Holtforth, M., Perry, J. C., Schneider, N., Dommann, E., Heer, S., et al. (2019). Comparison and change of defense mechanisms over the course of psychotherapy in patients with depression or anxiety disorder: 
evidence from a randomized controlled trial. J. Affect. Disord. 252, 212-220. doi: 10.1016/j.jad.2019.04.021

Barber, J. P., and Solomonov, N. (2019). Toward a personalized approach to psychotherapy outcome and the study of therapeutic change. World Psychiatry 18, 291-292. doi: 10.1002/wps.20666

Bateman, A. W., and Fonagy, P. (eds.). (2012). Handbook of Mentalizing in Mental Health Practice. Washington, DC: American Psychiatric Publishing, Inc.

Békés, V., Aafjes-van Doorn, K., Prout, T. A., and Hoffman, L. (2020). Stretching the analytic frame: analytic therapists' experiences with remote therapy during COVID-19. J. Am. Psychoanal. Assoc. 68, 437-446. doi: 10.1177/0003065120939298

Bhatia, M., Petraglia, J., de Roten, Y., and Drapeau, M. (2017). Do therapists practicing psychoanalysis, psychodynamic therapy and short-term dynamic therapy address patient defences differently? Arch. Psychiatry Psychother. 19, 7-14. doi: 10.12740/APP/69642

Boldrini, T., Lo Buglio, G., Giovanardi, G., Lingiardi, V., and Salcuni, S. (2020). Defense mechanisms in adolescents at high risk of developing psychosis: an empirical investigation. Res. Psychother. 23:456. doi: 10.4081/ripppo.2020.456

Boldrini, T., Tanzilli, A., Pontillo, M., Chirumbolo, A., Vicari, S., and Lingiardi, V. (2019). Comorbid personality disorders in individuals with an at-risk mental state for psychosis: a meta-analytic review. Front. Psychiatry 10:429. doi: 10.3389/fpsyt.2019.00429

Bornstein, R. F. (2005). "Psychodynamic theory and personality disorders," in Handbook of Personology and Psychopathology, ed S. Strack (Hoboken, NJ: John Wiley and Sons Inc), 164-180.

Conversano, C., Ciacchini, R., Orrù, G., Di Giuseppe, M., Gemignani, A., and Poli, A. (2020a). Mindfulness, compassion, and self-Compassion among health care professionals: what's new? A systematic review. Front Psychol. 11:1683. doi: 10.3389/fpsyg.2020.01683

Conversano, C., and Di Giuseppe, M. (2021). Psychological factors as determinants of chronic conditions: clinical and psychodynamic advances. Front. Psychol. 12:635708. doi: 10.3389/fpsyg.2021.635708

Conversano, C., Di Giuseppe, M., Miccoli, M., Ciacchini, R., Gemignani, A., and Orrù, G. (2020b). Mindfulness, age and gender as protective factors against psychological distress during COVID-19 pandemic. Front. Psychol. 11:1900. doi: $10.3389 /$ fpsyg. 2020.01900

Cramer, P. (2007). Longitudinal study of defense mechanisms: late childhood to late adolescence. J. Pers. 75, 1-24. doi: 10.1111/j.1467-6494.2006.00430.x

Di Giuseppe, M., Ciacchini, R., Piarulli, A., Nepa, G., and Conversano, C. (2019a). Mindfulness disposition and defense style as positive responses to psychology distress in oncology professionals. Eur. J. Oncol. Nurs. 40, 104-110. doi: 10.1016/j.ejon.2019.04.003

Di Giuseppe, M., Gemignani, A., and Conversano, C. (2020a). Psychological resources against the traumatic experience of COVID-19. Clin. Neuropsychiatry 17, 85-87. doi: $10.36131 / \mathrm{cn} 20200210$

Di Giuseppe, M., Gennaro, A., Lingiardi, V., and Perry, J. C. (2019b). The role of defense mechanisms in emerging personality disorders in clinical adolescents. Psychiatry 82, 128-142. doi: 10.1080/00332747.2019.15 79595

Di Giuseppe, M., Perry, J. C., Conversano, C., Gelo, O., and Gennaro, A. (2020b). Defense mechanisms, gender, and adaptiveness in emerging personality disorders in adolescent outpatients. J. Nerv. Ment. Dis. 208, 933-941. doi: 10.1097/NMD.0000000000001230

Di Giuseppe, M., Perry, J. C., Lucchesi, M., Michelini, M., Vitiello, S., Piantanida, A., et al. (2020c). Preliminary reliability and validity of the DMRS-SR-30, a novel self-report based on the Defense Mechanisms Rating Scales. Front. Psychiatry 11:870. doi: 10.3389/fpsyt.2020.00870

Di Giuseppe, M., Perry, J. C., Petraglia, J., Janzen, J., and Lingiardi, V. (2014). Development of a Q-sort version of the defense mechanisms rating scales (DMRS-Q) for clinical use. J. Clin. Psychol. 70, 452-465. doi: 10.1002/jclp. 22089

Di Giuseppe, M., Prout, T. A., Fabiani, M., and Kui, T. (2020d). Defensive profile of parents of children with externalizing problems receiving Regulation-Focused Psychotherapy for Children (RFP-C): a pilot study. Mediterr. J. Clin. Psychol. 8:2515. doi: 10.6092/2282-1619/mjcp-2515

Di Giuseppe, M., Zilcha-Mano, S., Prout, T. A., Perry, J. C., Orrù, G., and Conversano, C. (2020e). Psychological impact of coronavirus disease 2019 among Italians during the first week of lockdown. Front. Psychiatry 11:576597. doi: $10.3389 /$ fpsyt.2020.576597
Elbay, R. Y., Kurtulmuş, A., Arpacioglu, S., and Karadere, E. (2020). Depression, anxiety, stress levels of physicians and associated factors in Covid-19 pandemics. Psychiatry Res. 290:113130. doi: 10.1016/j.psychres.2020.113130

Elkholy, H., Tawfik, F., Ibrahim, I., Salah El-Din, W., Sabry, M., Mohammed, S., et al. (2020). Mental health of frontline healthcare workers exposed to COVID-19 in Egypt: a call for action. Int. J. Soc. Psychiatry. doi: 10.1177/0020764020960192. [Epub ahead of print].

Fonagy, P., Gergely, G., and Target, M. (2008). "Psychoanalytic constructs and attachment theory and research," in Handbook of Attachment: Theory, Research, and Clinical Applications, eds J. Cassidy and P. R. Shaver (New York, NY: The Guilford Press), 783-810.

Franceschini, C., Musetti, A., Zenesini, C., Palagini, L., Scarpelli, S., Quattropani, M. C., et al. (2020). Poor sleep quality and its consequences on mental health during the covid-19 lockdown in Italy. Front. Psychol. 11:574475. doi: $10.3389 /$ fpsyg.2020.574475

Frisone, F., Settineri, S., Sicari, P. F., and Merlo, E. M. (2020). Gambling in adolescence: a narrative review of the last 20 years. J. Addic. Dis. 38, 438-457. doi: 10.1080/10550887.2020.1782557

Gabbard, G. O. (2014). Psychodynamic Psychiatry in Clinical Practice, 5th Edn. Washington, DC: American Psychiatric Association Publishing.

Gelo, O. C. G., Lagetto, G., Dinoi, C., Belfiore, E., Lombi, E., Blasi, S., et al. (2020). Which Methodological Practice(s) for Psychotherapy Science? A systematic review and a proposal. Integr. Psychol. Behav. Sci. 54, 215-248. doi: 10.1007/s12124-019-09494-3

Gelo, O. C. G., Vilei, A., Maddux, J. E., and Gennaro, A. (2015). Psychopathology as social construction: the case of anorexia nervosa. J. Constr. Psychol. 28, 105-125. doi: 10.1080/10720537.2013.858087

Gennaro, A., Kipp, S., Viol, K., de Felice, G., Andreassi, S., Aichhorn, W., et al. (2020). A phase transition of the unconscious: automated text analysis of dreams in psychoanalytic psychotherapy. Front. Psychol. 11:1667. doi: $10.3389 /$ fpsyg. 2020.01667

Giordano, C., Lo Coco, G., Salerno, L., and Di Blasi, M. (2021). The role of emotion dysregulation in adolescents' problematic smartphone use: a study on adolescent/parents triads. Comput. Hum. Behav. 11:106632. doi: 10.1016/j.chb.2020.106632

Giovanardi, G., Mundo, E., and Lingiardi, V. (2020). Paola on the couch: the quest for feminine identity in an empirically supported psychoanalytic psychotherapy of a trans woman. Psychoanal. Psychol. doi: 10.1037/pap0000330. [Epub ahead of print].

Goldman, R. E., Hilsenroth, M. J., Gold, J. R., Cersosimo, B. H., Levy, S. R., and Owen, J. J. (2018). Psychotherapy integration and borderline personality pathology: an examination of treatment outcomes. J. Psychother. Integr. 28, 444-461. doi: 10.1037/int0000124

Gray, N. S., O'Connor, C., Knowles, J., Pink, J., Simkiss, N. J., Williams, S. D., et al. (2020). The influence of the COVID-19 pandemic on mental well-being and psychological distress: impact upon a single country. Front. Psychiatry11:594115. doi: 10.3389/fpsyt.2020.594115

Hilsenroth, M. J., Katz, M., and Tanzilli, A. (2018). Psychotherapy research and the psychodynamic diagnostic manual (PDM-2). Psychoanal. Psychol. 35, 320-327. doi: $10.1037 /$ pap0000207

Hilsenroth, M. J., and Pitman, S. R. (2019). "Working with cyclical relational patterns in contemporary psychodynamic psychotherapy," in Contemporary Psychodynamic Psychotherapy, eds D. Kealy and J. S. Ogrodniczuk (Waltham, MA: Academic Press), 19-31. doi: 10.1016/B978-0-12-813373-6.00002-7

Hoffman, L., and Prout, T. A. (2020). Helping parents spare the rod: addressing their unbearable emotions. Psychoanal. Study Child 73, 46-61. doi: $10.1080 / 00797308.2020 .1690867$

Hoffman, L., Rice, T., and Prout, T. (2016). Psychological Issues Book Series. Manual of Regulation-Focused Psychotherapy for Children (RFP-C) with Externalizing Behaviors: A Psychodynamic Approach. Routledge: Taylor and Francis Group. doi: 10.4324/9781315736648

Iasevoli, M., Giantin, V., Voci, A., Valentini, E., Zurlo, A., Maggi, S., et al. (2012). Discussing end-of-life care issues with terminally ill patients and their relatives: comparisons among physicians, nurses and psychologists. Aging Clin. Exp. Res. $24,35-42$.

Kernberg, O. F. (1988). Object relations theory in clinical practice. Psychoanal. Q. 57, 481-504. doi: 10.1080/21674086.1988.11927218

Kramer, U. (2019). Personality, personality disorders, and the process of change. Psychother. Res. 29, 324-336. doi: 10.1080/10503307.2017.1377358 
Leibovich, L., Front, O., McCarthy, K. S., and Zilcha-Mano, S. (2020). How do supportive techniques bring about therapeutic change: the role of therapeutic alliance as a potential mediator. Psychotherapy 57, 151-159. doi: $10.1037 /$ pst0000253

Lenzo, V., Sardella, A., Martino, G., and Quattropani, M. C. (2020). A systematic review of metacognitive beliefs in chronic medical conditions. Front. Psychol. 10:2875. doi: 10.3389/fpsyg.2019.02875

Lenzo,V., Quattropani, M. C., Sardella, A.,Martino, G., and Bonanno, G. A. (2021). Depression, anxiety, and stress among healthcare workers during the COVID19 outbreak and relationships with expressive flexibility and context sensitivity. Front. Psychol. 12:623033. doi: 10.3389/fpsyg.2021.623033

Lingiardi, V., Gazzillo, F., Colli, A., De Bei, F., Tanzilli, A., Di Giuseppe, M., et al. (2010). Diagnosis and assessment of personality, therapeutic alliance and clinical exchange in psychotherapy research. Res. Psychother. 2, 97-124.

Lingiardi, V., and Giovanardi, G. (2017). Challenges in assessing personality of individuals with Gender Dysphoria with the SWAP-200. J. Endocrinol. Invest. 40, 693-703. doi: 10.1007/s40618-017-0629-7

Lingiardi, V., and McWilliams, N. (2015). The psychodynamic diagnostic manual - 2nd edition (PDM-2). World Psychiatry 14, 237-239. doi: 10.1002/wps.20233

Lingiardi, V., McWilliams, N., Bornstein, R. F., Gazzillo, F., and Gordon, R. M. (2015). The psychodynamic diagnostic manual version 2 (PDM-2): assessing patients for improved clinical practice and research. Psychoanal. Psychol. 32, 94-115. doi: 10.1037/a0038546

Lo Coco, G., Melchiori, F., Oieni, V., Infurna, M. R., Strauss, B., Schwartze, D., et al. (2019a). Group treatment for substance use disorder in adults: a systematic review and meta-analysis of randomized-controlled trials. J. Subst. Abuse Treat. 99, 104-116. doi: 10.1016/j.jsat.2019.01.016

Lo Coco, G., Salerno, L., Franchina, V., La Tona, A., Di Blasi, M., and Giordano, C. (2020). Examining bi-directionality between Fear of Missing Out and problematic smartphone use. A two-wave panel study among adolescents. Addict. Behav. 106:106360. doi: 10.1016/j.addbeh.2020.106360

Lo Coco, G., Salerno, L., Ingoglia, S., and Tasca, G. A. (2021). Self-esteem and binge eating: do patients with binge eating disorder endorse more negatively worded items of the Rosenberg Self-Esteem Scale?. J. Clin. Psychol. 77, 818-836. doi: $10.1002 /$ jclp. 23065

Lo Coco, G., Tasca, G. A., Hewitt, P. L., Mikail, S. F., and Kivlighan, D. M. (2019b). Ruptures and repairs of group therapy alliance. An untold story in psychotherapy research. Res. Psychother. 22:352. doi: 10.4081/ripppo.2019.352

Luyten, P., and Blatt, S. J. (2015). "The psychodynamic approach to diagnosis and classification," in Handbook of Psychodynamic Approaches to Psychopathology, eds P. Luyten, L. C. Mayes, P. Fonagy, M. Target, and S. J. Blatt (New York, NY: The Guilford Press), 87-109.

Maffei, C., Fossati, A., Lingiardi, V., Madeddu, F., Borellini, C., and Petrachi, M. (1995). Personality maladjustment, defenses, and psychopathological symptoms in nonclinical subjects. J. Pers. Disord. 9, 330-345. doi: 10.1521/pedi.1995.9.4.330

Marazziti, D., Pozza, A., Di Giuseppe, M., and Conversano, C. (2020). The psychosocial impact of COVID-19 pandemic in Italy: a lesson for mental health prevention in the first severely hit European country. Psychol. Trauma 12, 531-533. doi: $10.1037 /$ tra0000687

Marčinko, D., Jakovljević, M., Jakšić, N., Bjedov, S., and Mindoljević Drakulić, A. (2020). The importance of psychodynamic approach during COVID-19 pandemic. Psychiatr. Danub 32, 15-21. doi: 10.24869/psyd.2020.15

Martino, G., Caputo, A., Schwarz, P., Bellone, F., Fries, W., Quattropani, M. C., et al. (2020a). Alexithymia and inflammatory bowel disease: a systematic review. Front. Psychol. 11:1763. doi: 10.3389/fpsyg.2020.01763

Martino, G., Catalano, A., Agostino, R. M., Bellone, F., Morabito, N., Lasco, C. G., et al. (2020b). Quality of life and psychological functioning in postmenopausal women undergoing aromatase inhibitor treatment for early breast cancer. PLoS ONE 15:e0230681. doi: 10.1371/journal.pone.0230681

Mazza, C., Orrù, G., Burla, F., Monaro, M., Ferracuti, S., Colasanti, M., et al. (2019). Indicators to distinguish symptom accentuators from symptom producers in individuals with a diagnosed adjustment disorder: a pilot study on inconsistency subtypes using SIMS and MMPI-2-RF. PLoS ONE 14:e0227113. doi: 10.1371/journal.pone. 0227113

McCarthy, K. S., Zilcha-Mano, S., and Barber, J. P. (2019). "Process research in psychodynamic psychotherapy: interventions and the therapeutic relationship," in Contemporary Psychodynamic Psychotherapy, eds D.
Kealy and J. S. Ogrodniczuk (Waltham, MA: Academic Press), 75-88. doi: 10.1016/B978-0-12-813373-6.00005-2

Merlo, E. M., Stoian, A., Motofei, I. G., and Settineri, S. (2020). Clinical psychological figures in healthcare professionals: resilience and maladjustment as the "cost of care." Front. Psychol. 11:607783. doi: 10.3389/fpsyg.2020.607783

Meystre, C., Kramer, U., Despland, J.-N., and de Roten, Y. (2017). Insight level in the assimilation process: a comparison of good- and poor-outcome cases in short-term dynamic psychotherapy of depressive inpatients. Couns. Psychol. Q. 30, 134-151. doi: 10.1080/09515070.2016.1161598

Midgley, N., Anderson, J., Grainger, E., Nesic-Vuckovic, T., and Urwin, C. (eds.). (2009). Child Psychotherapy and Research: New Approaches, Emerging Findings. Routledge: Taylor and Francis Group. doi: 10.4324/9780203872154

Orrù, G., Ciacchini, R., Gemignani, A., and Conversano, C. (2020a). Psychological intervention measures during the COVID-19 pandemic. Clin. Neuropsychiatry 17, 76-79. doi: 10.36131/CN20200208

Orrù, G., Conversano, C., Malloggi, E., Francesconi, F., Ciacchini, R., and Gemignani, A. (2020b). Neurological complications of COVID-19 and possible neuroinvasion pathways: a systematic review. Int. J. Environ. Res. Public Health17:6688. doi: 10.3390/ijerph17186688

Orrù, G., Marzetti, F., Conversano, C., Vagheggini, G., Miccoli, M., Ciacchini, R., et al. (2021). Secondary traumatic stress and burnout in healthcare workers during COVID-19 outbreak. Int. J. Environ. Res. Public Health 18:337. doi: 10.3390/ijerph18010337

Parola, A., Rossi, A., Tessitore, F., Troisi, G., and Mannarini, S. (2020). Mental health through the covid-19 quarantine: a growth curve analysis on italian young adults. Front. Psychol. 11:567484. doi: 10.3389/fpsyg.2020.567484

Perry, J. C. (1990). Defense Mechanism Rating Scales (DMRS). 5th Edn. Cambridge: Author.

Perry, J. C. (2014). Anomalies and specific functions in the clinical identification of defense mechansims. J. Clin. Psychol. 70, 406-418. doi: 10.1002/jclp.22085

Perry, J. C., Banon, E., and Bond, M. (2020). Change in defense mechanisms and depression in a pilot study of antidepressive medications plus 20 sessions of psychotherapy for recurrent major depression. J. Nerv. Ment. Dis. 208, 261-268. doi: $10.1097 /$ NMD.0000000000001112

Perry, J. C., and Bond, M. (2012). Change in defense mechanisms during longterm psychotherapy and five-year outcome. Am. J. Psychiatry 169, 916-925. doi: 10.1176/appi.ajp.2012.11091403

Perry, J. C., Knoll, M., and Tran, V. (2019). "Motives, defenses, and conflicts in the dynamic formulation for psychodynamic psychotherapy using the Idiographic Conflict Formulation method," in Case Formulation for Personality Disorders, ed U. Kramer (New York, NY: Elsevier), 203-224. doi: 10.1016/B978-0-12-813521-1.00011-4

Prout, T. A., Chacko, A., Spigelman, A., Aizin, S., Burger, M., Chowdhury, T., et al. (2018a). Bridging the divide between psychodynamic and behavioral approaches for children with oppositional defiant disorder. J. Infant Child Adolesc. Psychother. 17, 364-377. doi: 10.1080/15289168.2018.1519755

Prout, T. A., Goodman, G., Hoffman, L., Rice, T., and Sherman, A. (2018b). Expert clinicians' prototype of an ideal treatment in regulation-focused psychotherapy for children (RFP-C). J. Psychother. Integr. 28, 401-412. doi: $10.1037 /$ int 0000102

Prout, T. A., Rice, T., Murphy, S., Gaines, E., Aizin, S., Sessler, D., et al. (2019). Why is it easier to get mad than it is to feel sad? Pilot study of regulation-focused psychotherapy for children. Am. J. Psychother. 72, 2-8. doi: 10.1176/appi.psychotherapy.20180027

Prout, T. A., Zilcha-Mano, S., Aafjes-van Doorn, K., Békés, V., Christman-Cohen, I., Whistler, K., et al. (2020). Identifying predictors of psychological distress during COVID-19: a machine learning approach. Front. Psychol. 11:586202. doi: $10.3389 /$ fpsyg.2020.586202

Rocco, D., Pastore, M., Gennaro, A., Salvatore, S., Cozzolino, M., and Scorza, M. (2018). Beyond verbal behavior: an empirical analysis of speech rates in psychotherapy sessions. Front. Psychol. 9:978. doi: 10.3389/fpsyg.2018. 00978

Rosa, V., Tomai, M., Lauriola, M., Martino, G., and Di Trani, M. (2019). Body mass index,personality traits, and body image in Italian preadolescents: an opportunity for overweight prevention. Psihologija 52, 379-393. doi: 10.2298/PSI181121009R

Salvatore, S. (2019). Beyond the meaning given. The meaning as explanandum. Integr. Psychol. Behav. Sci. 53, 632-643. doi: 10.1007/s12124-019-9472-z 
Salvatore, S., Gelo, O. C. G., Gennaro, A., Metrangolo, R., Terrone, G., Pace, V., et al. (2017). An automated method of content analysis for psychotherapy research: a further validation. Psychother. Res. 27, 38-50. doi: 10.1080/10503307.2015.1072282

Salvatore, S., Tschacher, W., Gelo, O. C., and Koch, S. C. (2015). Editorial: dynamic systems theory and embodiment in psychotherapy research. A new look at process and outcome. Front. Psychol. 6:914. doi: 10.3389/fpsyg.2015.00914

Sardella, A., Lenzo, V., Bonanno, G. A., Martino, G., Basile, G., and Quattropani, M. C. (2021). Dispositional optimism and context sensitivity: psychological contributors to frailty status among elderly outpatients. Front. Psychol. 11:621013. doi: 10.3389/fpsyg.2020.621013

Sartori, G., Zangrossi, A., Orrù, G., and Monaro, M. (2017). "Detection of malingering in psychic damage ascertainment," in P5 Medicine and Justice, ed S. Davide Ferrara (Cham: Springer), 330-341. doi: 10.1007/978-3-319-67092-8_21

Shen, K., Yang, Y., Wang, T., Zhao, D., Jiang, Y., Jin, R., et al. (2020). Diagnosis, treatment, and prevention of 2019 novel coronavirus infection in children: experts' consensus statement. World J. Pediatr. 16, 223-231. doi: 10.1007/s12519-020-00343-7

Singh, S., Roy, D., Sinha, K., Parveen, S., Sharma, G., and Joshi, G. (2020). Impact of COVID-19 and lockdown on mental health of children and adolescents: a narrative review with recommendations. Psychiatry Res. 293:113429. doi: 10.1016/j.psychres.2020.113429

Solomonov, N., Kuprian, N., Zilcha-Mano, S., Muran, J. C., and Barber, J. P. (2020). Comparing the interpersonal profiles of obsessive-compulsive personality disorder and avoidant personality disorder: are there homogeneous profiles or interpersonal subtypes?. Pers. Disord. 11, 348-356. doi: 10.1037/per0000391

Solomonov, N., van-Doorn, K. A., Lipner, L. M., Gorman, B. S., Milrod, B., Rudden, M. G., et al. (2019). Panic-focused reflective functioning and comorbid borderline traits as predictors of change in quality of object relations in panic disorder treatments. J. Contemp. Psychothery 49, 255-264. doi: 10.1007/s10879-019-09434-7

Starrs, C. J., and Perry, J. C. (2018). Coping action patterns as mechanisms of change across psychotherapies: three case examples of personality disorders with recurrent major depression. J. Pers. Disord. 32, 58-74. doi: 10.1521/pedi.2018.32.supp.58

Talia, A., Taubner, S., and Miller-Bottome, M. (2019). Advances in research on attachment-related psychotherapy processes: seven teaching points for trainees and supervisors. Res. Psychother. 22:405. doi: 10.4081/ripppo.2019.405
Tanzilli, A., Colli, A., Del Corno, F., and Lingiardi, V. (2016). Factor structure, reliability, and validity of the therapist response questionnaire. Pers. Disord. 7, 147-158. doi: 10.1037/per0000146

Tanzilli, A., Lingiardi, V., and Hilsenroth, M. (2018). Patient SWAP-200 personality dimensions and FFM traits: do they predict therapist responses? Pers. Disord. 9, 250-262. doi: 10.1037/per0000260

Terrone, G., Musetti, A., Raschielli, S., Marino, A., Costrini, P., Mossi, P., et al. (2018). Attachment relationships and internalization and externalization problems in a group of adolescents with pathological gambling disorder. Clin. Neuropsychiatry 15, 66-74.

Vaillant, G. E. (1977). Adaptation to Life. Boston: Little, Brown.

Vaillant, G. E. (1992). Ego Mechanisms of Defense: A Guide for Clinicians and Researchers. Washington D.C.: American Psychiatric Press.

Venuleo, C., Gelo, O. C. G., and Salvatore, S. (2020). Fear, affective semiosis, and management of the pandemic crisis: COVID-19 as semiotic vaccine? Clin. Neuropsychiatry 17, 117-130. doi: 10.36131/CN20200218

Walker, G., and McCabe, T. (2021). Psychological defence mechanisms during the COVID-19 pandemic: a case series. Eur. J. Psychiatry 35, 41-45. doi: 10.1016/j.ejpsy.2020.10.005

Zilcha-Mano, S., Eubanks, C. F., Bloch-Elkouby, S., and Muran, J. C. (2020). Can we agree we just had a rupture? Patient-therapist congruence on ruptures and its effects on outcome in brief relational therapy versus cognitivebehavioral therapy. J. Couns. Psychol. 67, 315-325. doi: 10.1037/cou00 00400

Zilcha-Mano, S., and Ramseyer, F. T. (2020). Innovative approaches to exploring processes of change in counseling psychology: insights and principles for future research. J. Couns. Psychol. 67, 409-419. doi: 10.1037/cou00 00426

Conflict of Interest: The author declares that the research was conducted in the absence of any commercial or financial relationships that could be construed as a potential conflict of interest.

Copyright (c) 2021 Conversano. This is an open-access article distributed under the terms of the Creative Commons Attribution License (CC BY). The use, distribution or reproduction in other forums is permitted, provided the original author(s) and the copyright owner(s) are credited and that the original publication in this journal is cited, in accordance with accepted academic practice. No use, distribution or reproduction is permitted which does not comply with these terms. 